\title{
The cytokine profile of OCD: pathophysiological insights
}

\section{Donatella Marazziti \\ Federico Mucci \\ Amedeo Lombardi \\ Valentina Falaschi \\ Liliana Dell'Osso}

Dipartimento di Medicina Clinica e Sperimentale, Section of Psychiatry, University of Pisa, Pisa, Italy
Correspondence: Donatella Marazziti Department of Clinical and Experimental Medicine, Section of Psychiatry,

University of Pisa, Via Roma, 67, 56100

Pisa, Italy

$\mathrm{Tel}+39502219768$

Fax +3950 22I 9787

Email dmarazzipsico.med.unipi.it
This article was published in the following Dove Press journal: International Journal of Interferon, Cytokine and Mediator Research 29 September 2015

Number of times this article has been viewed

\begin{abstract}
Obsessive-compulsive disorder (OCD) is a psychiatric condition characterized by the presence of obsessions and/or compulsions, which has been commonly associated with alterations of some neurotransmitters systems, in particular, the serotonin and dopamine ones. However, it is now evident that these supposed disturbances cannot explain the development of this disorder, and so other possible mechanisms have been invoked, such as those involving the immune system that is attracting an increasing interest. According to the current literature, immune system alterations are reported in OCD of both children and adults. In children, it has been widely described as a clinical syndrome resulting from infections driven by group $\mathrm{A}$ $\beta$-hemolytic streptococci and characterized by rheumatic fever, OCD, and neurological symptoms called "pediatric autoimmune neuropsychiatric disorders associated with streptococcus". In adults, available findings are meager and controversial, although intriguing. Such preliminary findings underline the presence of OCD in a number of autoimmune disorders, as well as of alterations of different immune parameters in OCD patients. This paper aims at presenting an exhaustive review of the role of the immune system in the development of OCD, with a major focus on the possible pathophysiological role of cytokines that seems to open novel treatment options.
\end{abstract}

Keywords: OCD, cytokines, immune system, inflammation, PANDAS

\section{Introduction}

Increasing data suggest that the immune system may be involved in the pathophysiology of different neuropsychiatric disorders, such as depression, ${ }^{1}$ dementia, ${ }^{2}$ schizophrenia, ${ }^{3}$ posttraumatic stress disorder, ${ }^{4}$ panic disorder, ${ }^{5}$ social phobia, ${ }^{6}$ and obsessive-compulsive disorder (OCD), while supporting the notion of "systemic disease". Interestingly, immune system alterations have been described in both children and adult OCD patients. In children, the main data are derived from a clinical syndrome resulting from infections driven by group A $\beta$-hemolytic streptococcus (GAS), in which changes of the immune system are associated with the development of rheumatic fever (RF), OCD, and neurological symptoms, namely, Sydhenam chorea (SC). Since RF and SC are secondary to GAS infections, the higher incidence of OCD and tics has also been related to the same process. Therefore, the National Institutes of Mental Health group devoted to OCD study proposed the term "pediatric autoimmune neuropsychiatric disorders associated with streptococcus (PANDAS)" for this type of OCD frequent in children.? However, immunological disturbances do not seem to be limited only to childhood, but also to adulthood OCD, as a recent chart-review study ${ }^{8}$ concluded that adult OCD patients show an increased rate of immune-related diseases beyond that 
observed in other psychiatric disorders. ${ }^{9}$ Conversely, it is also true that there is a significant prevalence of comorbidity of OCD in patients suffering from other autoimmune diseases, such as systemic lupus erythematosus, thyroid dysfunction, ${ }^{10}$ and multiple sclerosis. ${ }^{11,12}$ However, despite the recent interest in immunological abnormalities in OCD, only a few studies have examined cytokines in this disorder. $^{13-16}$

This paper aims at reviewing the available data on immunological alterations in OCD, with a special focus on the possible role of cytokines in this complex disorder.

\section{$O C D$ and the immune system}

OCD is a common and debilitating psychiatric condition with specific symptoms that can be easily diagnosed, which are obsessions and/or compulsions. Obsessions are defined as recurrent and persistent thoughts, impulses, or images that cause anxiety and distress. Compulsions are repetitive behaviors or mental acts that a person feels driven to perform in response to an obsession, in order to reduce distress or a dreaded event. OCD has been recognized as a distinct nosological entity, separated from anxiety disorders in the latest edition of the Diagnostic and Statistical Manual of Mental Disorders fifth edition (DSM-5). ${ }^{17}$

The pathophysiology of OCD is still unknown; however, two neurotransmitters systems have been largely supposed to play a major role, in particular, the serotonin (5-HT) and dopamine (DA) systems. ${ }^{18}$ In any case, as the classical hypotheses cannot fully explain the complexity of this disorder, alternative possibilities have been put forward, such as those suggesting a possible implication of the immune system. Interestingly, different findings show relationships between 5-HT and the immune system. ${ }^{19}$ Indeed, the immune system, via interferon (IFN- $\alpha$ and IFN- $\gamma$ ), and tumor necrosis factor $\alpha$ (TNF- $\alpha$ ) can activate the indolamine-2,3-dehydrogenase (IDO) enzyme, ${ }^{20-23}$ which has the function of breaking down tryptophan and shunting its metabolism from 5-HT to kynurenine production. Therefore, an upregulation of the tryptophan-kynurenine pathway can indicate a deficiency of 5-HT that may underlie different psychiatric symptoms. In addition, kynurenine may provoke toxic effects on the central nervous system (CNS). Tryptophan 2,3-dioxygenase (activated by stress hormones) and IDO (activated by proinflammatory cytokines) are the two rate-limiting enzymes of kynurenine formation. Therefore, it is possible that the pathway of tryptophan-kynurenine represents a potential interaction between genetic and environmental factors involved in the pathophysiology of different psychiatric disorders, not only depression. ${ }^{24,25}$
The role of the DA system in the immune system is less clear. ${ }^{26,27}$ DA may activate human normal naive peripheral T-cells and trigger their adhesion to fibronectin, ${ }^{28}$ induce the chemotactic migration of naive $\mathrm{CD}^{+} \mathrm{T}^{+}$-cells ${ }^{29}$ and T-cell cytokine secretion (in particular TNF- $\alpha$ ) and the interleukin-10 (IL-10), and might probably activate T-cell function indirectly by suppressing T-regulatory cells. ${ }^{19,30}$ In addition, elevated levels of baseline cortisol have been widely described in OCD, ${ }^{31-33}$ although this is a controversial and unspecific finding. ${ }^{23,34-37}$

Despite the fact that cytokines studies have led to contradictory results, ${ }^{38}$ alterations of the immune system appear to contribute in pathophysiology of OCD, which is also associated with autoimmune disorders, streptococcal infections, and TNF- $\alpha$ polymorphisms. ${ }^{39,40}$ Moreover, even an inflammatory process caused by an acute or a chronic infection may be involved in the pathogenesis of OCD. OCD appears to share with other autoimmune conditions decreased levels of peripheral natural regulatory T-cells, suggesting a predisposition for autoimmune responses correlated to symptom severity. ${ }^{41,42}$ Decreased natural killer cell activity, increased $\mathrm{CD}^{+}$, and decreased $\mathrm{CD} 4^{+}$lymphocytes have been described in adult OCD patients and are related to disturbances of stress mechanisms. ${ }^{43}$ Moreover, reduced IL-1 $\beta$ levels ${ }^{15}$ and a trend toward low LPS-stimulated IL-6 levels in adult OCD patients have also been reported. ${ }^{44,45}$ Genetic influences and environmental triggers determine if and when the progression from benign autoimmunity to pathogenic autoimmunity occurs. ${ }^{9}$

\section{GAS infection and neuropsychiatric diseases RF and SC}

Although the incidence of pediatric streptococcal infections is extremely high, only a minority of children with such an infection develop a neuropsychiatric illness. ${ }^{9}$

When the infection is determined to be due to GAS, its common CNS autoimmune complication is RF and its neuropsychiatric expression is $\mathrm{SC}{ }^{46}$ The presence of psychiatric disorders in patients with a previous history of RF suggests that GAS may trigger OCD and related disorders that may persist throughout life regardless of GAS reinfections. The risk of developing OCD seems to occur only during acute episodes of RF. ${ }^{9}$ Family studies suggested that this relationship could be familial based as OCD-related and anxiety disorders, such as generalized anxiety disorders and separation anxiety, aggregate more frequently in first-degree relatives of RF probands, when compared with control subjects. ${ }^{47,48}$ An interesting finding in 
the search for candidate genes is the association of two polymorphisms of the promoter region of the TNF- $\alpha$ gene with both OCD and RF, as TNF- $\alpha$ is a proinflammatory cytokine involved in RF and several other autoimmune diseases. ${ }^{39,49}$ Such a finding would indicate the presence of a shared genetic vulnerability. ${ }^{50}$ The relationship between RF and OCD is strongly supported by the clinical evidence of high incidence of obsessions and/or compulsions not only in SC subjects ${ }^{51,52}$ but also in children with GAS infection without SC., ${ }^{9,53-55}$

\section{PANDAS}

PANDAS is commonly characterized by specific OCD symptoms, that is, to say, obsessions and compulsions, and neurological disturbances, such as choreiform movements. ${ }^{9,42,56}$ In PANDAS, cross-reacting antibodies against putamen have been observed, the so-called D8-17,,$^{55,58}$ even if the exact role of these antibodies is unclear as their precise involvement in OC symptomatology mechanism has not yet been explained. In any case, the presence of antibodies against brain in OCD patients would be supporting evidence that autoimmune activity may be involved in CNS damage. ${ }^{9,58}$

Even in RF patients, OCD symptoms precede the appearance of any motoric manifestation by days or weeks. ${ }^{53}$ Symptom presentation is also influenced by sex, with boys more likely to present with tics and girls more likely to present with chorea like movements. ${ }^{9}$ A child's risk of developing PANDAS is related to his or her genetic predisposition and to pathogens and environmental factors. Other trigger factors are supposed to be infections and generic stress, ${ }^{59,60}$ with a chronically activated immune system predisposing the triggering of the symptoms. An epidemiological study showed that the risk of developing a tic disorder was significantly increased with a previous history of multiple GAS infections..$^{9,61}$

\section{Cytokines}

Cytokines are soluble glycoproteins of low molecular weight produced by different cellular types in all organs. ${ }^{62}$ An altered cytokine production can provoke a cascade of detrimental effects on immunological and inflammatory responses that might contribute to the development of infectious diseases and progression of autoimmunity. ${ }^{39,63}$ TNF- $\alpha$ and IL- 6 and (IL) $-1 \beta$ are among the most extensively investigated cytokines in OCD.

\section{TNF- $\alpha$}

Macrophages and circulating monocytes produce TNF$\alpha$, which has important functions in several infectious, inflammatory, and autoimmune conditions ${ }^{64}$ Its plasma levels are influenced by age, body mass index, sex, time of the day, medicine intake, and other factors. ${ }^{16,39,66,67}$ Finally, there is evidence that this glycoprotein affects central processes directly or indirectly through stimulation of vagal afferents and stimulates its own production and that of IL-1 $\beta$, like other proinflammatory cytokines. ${ }^{67-70}$

TNF- $\alpha$ plays a key role in the CNS function. ${ }^{16,71}$ Higher functions, such as memory and learning, at least impaired in some of the OCD subgroups, seem to be influenced by TNF- $\alpha$ and IL-6. ${ }^{72-76}$ Moreover, some studies have detected hippocampal alterations in $\mathrm{OCD},{ }^{77,78}$ a region modulated by TNF- $\alpha$ and IL- $6{ }^{72,79}$ In response to injury, TNF- $\alpha$ production is increased in the brain, where it may act with nitric oxide to regulate the blood-brain barrier. ${ }^{80}$ Moreover, TNF- $\alpha$ mediates activation of the adaptive immune system by stimulating dendritic cell (DC) migration to regional lymph nodes, where DCs mature and present antigen to lymphocytes. ${ }^{81,82}$ TNF- $\alpha$ and its receptors (TNFR1 and TNFR2) play an important role in innate and adaptive immunity. ${ }^{83}$ Tumor necrosis factor- $\alpha$ gene is located on chromosome $6 \mathrm{p} 21.3$, a region that has been found to be associated with OCD. ${ }^{84}$

Patients with OCD showed increased plasma levels of sTNFR1, sTNFR2, and chemokines CXCL8, CCL3, that have been related even to specific symptom clusters or dimensions, although data are really meager and should be considered as just mere suggestions. ${ }^{85-89}$ Although no difference was found in TNF- $\alpha$ levels between OCD patients and control subjects, the first group showed increased plasma levels of sTNFR1 and sTNFR2 that suggest the presence of a mild inflammatory state. ${ }^{90}$ The production and activity of TNF- $\alpha$ may be estimated by measuring the plasma levels of sTNFR1 and sTNFR2. ${ }^{91,92}$

Interestingly, a high frequency of polymorphisms in the promoter region of the TNF- $\alpha$ gene has been described in OCD patients..$^{93}$ It is also noteworthy to mention the relationship between the $308 \mathrm{G} / \mathrm{A}$ polymorphism and RF or other autoimmune disorders, in particular, lupus erythematosus, characterized by neuropsychiatric symptoms. ${ }^{94}$

It has been suggested that the polymorphism at 308G/A affects TNF- $\alpha$ transcription. Studies with both positive ${ }^{95,96}$ and negative ${ }^{97-99}$ findings correlating TNF- $\alpha$ transcription with TNF- $\alpha$ polymorphisms have been published. Results from a recent study suggest that the TNF- $\alpha-308 \mathrm{G}$ allele cosegregates with high serum TNF- $\alpha$ level in family studies. ${ }^{65}$ Similarly, controversial reports concerning the TNF- $\alpha-238$ G/A polymorphism are also found in the literature, ${ }^{100-103}$ with the suggestion that the presence of the A allele may lead to increased transcription of TNF- $\alpha$. Finally, considering that 
TNF plasma levels vary with several factors, it is possible that the presence of a polymorphism may not be sufficient to explain TNF plasma levels that result from genetic and environmental factors. Furthermore, changes in behavior may probably be related to changes in the CNS through local production of cytokines such as TNF and not to plasma levels of TNF- $\alpha .^{39,105}$ Moreover, approximately two-thirds of adults with OCD have comorbidity of mood disorder. A meta-analysis has previously demonstrated that several proinflammatory cytokines, including TNF- $\alpha$ and IL-6, are elevated in depressed patients. ${ }^{107}$

\section{IL-6}

Several studies demonstrated that IL-6 acts on different cells and also that it is involved in the regulation of immune response, acute phase reaction, and in the pathogenesis of autoimmune and inflammatory disease. ${ }^{108}$ IL-6 is synthesized and expressed in small amounts even in the CNS. ${ }^{9,109}$ It is supposed to be important in neuroinflammation and brain-specific activation of microglia and astrocytes that may lead to neurodegenerative disorders. ${ }^{82,110}$

Only OCD patients taking specific drugs for the disorder seemed to be characterized by significantly lower plasma levels of IL-6, although this finding was not replicated in drug-free patients. It is, however, noteworthy that in another study drug-free OCD patients showed increased IL-6 concentrations. ${ }^{16}$ Therefore, there is a great need of further data for commenting on the possible role of IL-6 in OCD.

\section{IL-I $\beta$}

Blood monocytes and tissue macrophages, such as microglia, are the major sources of production of IL-1 $\beta$, a proinflammatory cytokine, through activation of macrophage and lymphocyte functions. ${ }^{109-112}$ In addition, IL-1 $\beta$ promotes the expression of other mediators and fever and stimulates the production of Il-6 by endothelial cells ${ }^{109-113}$ and also of a variety of cellmediated immune reactions. ${ }^{114-116}$ Only one paper ${ }^{5}$ and one meta-analysis demonstrated a significant reduction in IL- $1 \beta$ plasma levels in OCD patients compared with control subjects, and so no clear conclusion can be drawn on the involvement of this cytokines in OCD pathophysiology. ${ }^{82}$

\section{Treatment implications}

The pharmacological treatment of OCD represents one of the most successful achievements of the last decades of previous millennium, when it was demonstrated that this disorder responds specifically to drugs enhancing the 5-HT levels, in particular, to clomipramine, a tricyclic antidepressant, and the selective serotonin reuptake inhibitors (SSRIs; fluoxetine, fluvoxamine, paroxetine, sertraline, citalopram, and escitalopram). However, similar to what occurs in other psychiatric conditions, one third of OCD patients do not respond to first-line drugs or different augmentation strategies. Therefore, there is a great need for novel treatments in OCD, which might involve other neurotransmitters besides the classical 5-HT and DA, such as the glutamate, or second messenger modulators, ie, inositol, or immune-modulator compounds. ${ }^{17,117,118}$

As far as PANDAS is concerned, the difficulty in distinguishing it from other phenotypes of OCD or tics, and occasionally from SC, makes it difficult to establish practical treatment protocols. In spite of the fact that the pathophysiology of PANDAS has not yet been fully clarified, the current treatment for young patients fulfilling the PANDAS diagnostic criteria continues to be the standard-of-care practices for patients who suffer from OCD or Tourette's syndrome. In any case, conclusive evidence that the antibiotics reduced clinical exacerbations was found in a clinical trial involving the use of prophylactic oral penicillin in treating apparent episodes of PANDAS. The successful treatment of PANDAS children with a trial of plasmapheresis or intravenous immunoglobulin indirectly supported the immunological etiology of at least one subtype of OCD and tics disorder. ${ }^{9}$

The different immunological abnormalities described in different psychiatric disorders, including OCD, support that there is a potential role for anti-inflammatory agents in their treatment. Cycloxygenase (COX)-2 is an enzyme that is expressed in brain cells, which converts arachidonic acid to prostaglandin $\mathrm{H} 2$ that is converted by specific tissue isomerases in inflammatory products (tromboxanes, prostacyclins, and prostaglandins), including prostaglandins D2 and E2. Receptors for prostaglandins E2 are present in most brain cells. ${ }^{119}$ The production of proinflammatory cytokines, such as lymphocytes Th1-like cytokines, type- 1 and type- 2 immune response, ${ }^{120}$ and neuronal death induced by kainic acid, are all reduced by COX-2 inhibitors. The therapeutic effect of COX-2 inhibitors seems to be mediated by glutamatergic processes. Recently, it was shown that celecoxib (COX-2 inhibitor) may be used as augmentation strategy of fluoxetine, as it accelerated the onset of therapeutic effects compared to treatment with fluoxetine alone. The effect of celecoxib on OCD can be explained by some immunological mechanisms, such as inhibition of the synthesis of prostaglandins ${ }^{121}$ (in particular PGE2), and increased noradrenergic and serotonergic neurotransmission. ${ }^{120-123}$ These findings, although preliminary, would indicate that COX-2 inhibitors 
may be a new kind of treatment for OCD. However, there are probably different degrees of inflammation disturbances in OCD, and perhaps the assessment of plasma cytokine levels before and after treatment may be useful in predicting the possible response to COX-2 inhibitors. ${ }^{42}$

Interestingly, immune cell alterations seem to normalize after successful treatment with different SSRIs in adult OCD patients. $^{124}$

\section{Conclusion}

Scattered findings suggest that there are unequivocal immune changes in at least some subgroups of OCD patients, in both childhood and adulthood. In childhood, a strong relationship between GAS infection and the development of a clinical syndrome defined PANDAS was described, which is often characterized by neuropsychiatric symptoms, including symptoms of the OCD. In adult OCD patients, although the sample sizes were small and the patients heterogenous, alterations of different immunological parameters have been reported, in particular, some cytokines, especially $\mathrm{TNF} \alpha$, IL-6, and IL-1 $\beta$.

Altered levels of selected cytokines may support the hypothesis of immunologic involvement in the pathophysiology of OCD, as well as that different OCD symptoms/dimensions may be related to distinctive immune profiles. Furthermore, the fact that there is a preliminary evidence of possible efficacy of some immunotherapeutic treatments, such as antibiotic prophylaxis, on OCD symptoms would suggest a supportive role for immune triggers in the onset or worsening of these conditions and provide additional tools for improving outcome.

Similarly, although the first data on the possible efficacy of immune modulators, such as COX inhibitors, are promising, nevertheless they need to be supported by further and more robust data.

\section{Disclosure}

The authors report no conflicts of interests in this work.

\section{References}

1. Connor TJ, Leonard BE. Depression, stress and immunological activation: the role of cytokines in depressive disorders. Life Sci. 1998;62(7):583-606.

2. Leonard BE. Changes in the immune system in depression and dementia: causal or co-incidental effects? Int J Dev Neurosci. 2001;19(3):305-312.

3. Hinze-Selch D, Pollmächer T. In vitro cytokine secretion in individuals with schizophrenia: results, confounding factors, and implications for further research. Brain Behav Immun. 2001;15(4):282-318.

4. Maes M, Lin AH, Delmeire L, et al. Elevated serum interleukin-6 (IL-6) and IL-6 receptor concentrations in posttraumatic stress disorder following accidental man-made traumatic events. Biol Psychiatry. 1999;45(7): 833-839.
5. Brambilla F, Bellodi L, Perna G. Plasma levels of tumor necrosis factor- $\alpha$ in patients with panic disorder: effect of alprazolam therapy. Psychiatry Res. 1999;89(1):21-27.

6. Rapaport MH, Stein MB. Serum interleukin-2 and soluble interleukin-2 receptor levels in generalized social phobia. Anxiety. 1994;1(2):50-53.

7. Swedo SE, Leonard HL, Garvey M, et al. Pediatric autoimmune neuropsychiatric disorders associated with streptococcal infections: clinical description of the first 50 cases. Am J Psychiatry. 1998;155(2): 264-271.

8. Dinn WM, Harris CL, McGonigal KM, Raynard RC. Obsessivecompulsive disorder and immunocompetence. Int J Psychiatry Med. 2001;31(3):311-320.

9. Murphy TK, Sajid MW, Goodman WK. Immunology of obsessivecompulsive disorder. Psychiatr Clin North Am. 2006;29(2):445-469.

10. Placidi GP, Boldrini M, Patronelli A, et al. Prevalence of psychiatric disorders in thyroid diseased patients. Neuropsychobiology. 1998; 38(4):222-225.

11. George MS, Kellner CH, Fossey MD. Obsessive-compulsive symptoms in a patient with multiple sclerosis. J Nerv Ment Dis. 1989;177(5): 304-305.

12. Miguel EC, Stein MC, Rauch SL, O’Sullivan, Stern TA, Jenike MA. Obsessive-compulsive disorder in patients with multiple sclerosis. J Neuropsychiatry Clin Neurosci. 1995;7(4):507-510.

13. Maes M, Meltzer HY, Bosmans E. Psychoimmune investigation in obsessive-compulsive disorder: assays of plasma transferrin, IL-2 and IL-6 receptor, and IL-1 beta and IL-6 concentrations. Neuropsychobiology. 1994;30(2-3):57-60.

14. Weizman R, Laor N, Barber Y, et al. Cytokine production in obsessivecompulsive disorder. Biol Psychiatry. 1996;40(9):908-912.

15. Brambilla F, Perna G, Bellodi L, et al. Plasma interleukin-1 beta and tumor necrosis factor concentrations in obsessive-compulsive disorders. Biol Psychiatry. 1997;42(11):976-981.

16. Konuk N, Tekin IO, Ozturk U, et al. Plasma levels of tumor necrosis factor-alpha and interleukin-6 in obsessive compulsive disorder. Mediators Inflamm. 2007;2007:65704.

17. Marazziti D, Dell'Osso L. Why have early investigational therapies of obsessive-compulsive disorder failed to materialise? Expert Opin Investig Drugs. 2015;24(4):455-458.

18. Westenberg HG, Fineberg NA, Denys D. Neurobiology of obsessivecompulsive disorder: serotonin and beyond. CNS Spectr. 2007;12: 14-27.

19. Marazziti D, Consoli G, Masala I, Catena Dell'Osso M, Baroni S. Latest advancements on serotonin and dopamine transporters in lymphocytes. Mini Rev Med Chem. 2010;10(1):32-40.

20. Lestage J, Verrier D, Palin K, Dantzer R. The enzyme indoleamine 2,3-dioxygenase is induced in the mouse brain in response to peripheral administration of lipopolysaccharide and superantigen. Brain Behav Immun. 2002;16(5):596-601.

21. Kohl C, Sperner-Unterweger B. IDO and clinical conditions associated with depressive symptoms. Curr Drug Metab. 2007;8(3):283-287.

22. Marazziti D, Baroni S, Picchetti M, Piccinni A, Silvestri S, Dell'Osso L. New developments on the serotonin hypothesis of depression: shunt of tryptophan. Riv Psichiatr. 2013;48(1):23-34.

23. Fluitman S, Denys D, Vulink N, Schutters S, Heiknen C, Westenberg H. Lipopolysaccharide-induced cytokine production in obsessive-compulsive disorder and generalized social anxiety disorder. Psychiatry Res. 2010;178(2):313-316.

24. Baganz NL, Blakely RD. A dialogue between the immune system and brain, spoken in the language of serotonin. ACS Chem Neurosci. 2013;4(1):48-63.

25. Cappi C, Muniz RK, Sampaio AS, et al. Association study between functional polymorphisms in the TNF- $\alpha$ gene and obsessivecompulsive disorder. Arq Neuropsiquiatr. 2012;70(2):87-90.

26. Zacharko RM, Zalcman S, Macneil G, Andrews M, Mendella PD, Anisman H. Differential effects of immunologic challenge on selfstimulation from the nucleus accumbens and the substantia nigra. Pharmacol Biochem Behav. 1997;58(4):881-886. 
27. Devoino LV, Al'perina EL, Gevorgyan MM, Cheido MA. Involvement of dopamine D1 and D2 receptors in the rat nucleus accumbens in immunostimulation. Neurosci Behav Physiol. 2007:37(2):147-151.

28. Levite M, Chowers Y, Ganor Y, Besser M, Hershkovits R, Cahalon L. Dopamine interacts directly with its D3 and D2 receptors on normal human T cells, and activates $\beta 1$ integrin function. Eur J Immunol. 2001;31(12):3504-3512.

29. Watanabe Y, Nakayama T, Nagakubo D, et al. Dopamine selectively induces migration and homing of naive $\mathrm{CD} 8+\mathrm{T}$ cells via dopamine receptor D3. J Immunol. 2006;176(2):848-856.

30. Sarkar C, Basu B, Chakroborty D, et al. The immunoregulatory role of dopamine: an update. Brain Behav Immun. 2010;249:525-528.

31. Besser MJ, Ganor Y, Levite M. Dopamine by itself activates either D2, D3 or D1/D5 dopaminergic receptors in normal human T-cells and triggers the selective secretion of either IL-10, TNF- $\alpha$ or both. J Neuroimmunol. 2005;169(1-2):161-171.

32. Cosentino M, Fietta AM, Ferrari M, et al. Human CD4+CD25+ regulatory $\mathrm{T}$ cells selectively express tyrosine hydroxylase and contain endogenous catecholamines subserving an autocrine/paracrine inhibitory functional loop. Blood. 2007;109(2):632-642.

33. Catapano F, Monteleone P, Fuschino A, Maj M, Kemali D. Melatonin and cortisol secretion in patients with primary obsessive-compulsive disorder. Psychiatry Res. 1992;44(3):217-225.

34. Monteleone P, Catapano F, Tortorella A, Di Martino S, Maj M. Plasma melatonin and cortisol circadian patterns in patients with obsessive-compulsive disorder before and after fluoxetine treatment. Psychoneuroendocrinology. 1995;20(7):763-770.

35. Kluge M, Schüssler P, Künzel HE, Dresler M, Yassouridis A, Steiger A. Increased nocturnal secretion of ACTH and cortisol in obsessive compulsive disorder. J Psychiatr Res. 2007;41(11):928-933.

36. Bastani B, Nash JF, Meltzer HY. Prolactin and cortisol responses to MK-212, a serotonin agonist, in obsessive-compulsive disorder. Arch Gen Psychiatry. 1990;47(9):833-839.

37. Millet B, Touitou Y, Poirier MF, et al. Plasma melatonin and cortisol in patients with obsessive-compulsive disorder: relationship with axillary temperature, physical activity, and clinical symptoms. Biol Psychiatry. 1998;44(9):874-881.

38. Weizman R, Gil-Ad I, Hermesh H, Munitz H, Laron Z. Immunoreactive $\beta$-endorphin, cortisol, and growth hormone plasma levels in obsessivecompulsive disorder. Clin Neuropharmacol. 1990;13(4):297-302.

39. Fluitman SB, Denys DA, Heijnen CJ, Westenberg HG. Disgust affects TNF- $\alpha$, IL- 6 and noradrenalin levels in patients with obsessivecompulsive disorder. Psychoneuroendocrinology. 2010;35(6): 906-911.

40. Denys D, Fluitman S, Kavelaars A, Heijnen CJ, Westenberg HG. Effects of paroxetine and venlafaxine on immune parameters in patients with obsessive-compulsive disorder. Psychoneuroendocrinology. 2006; 31(3):355-360.

41. Hounie AG, Cappi C, Cordeiro Q, et al. TNF- $\alpha$ polymorphisms are associated with obsessive-compulsive disorder. Neurosci Lett. 2008; 442(2):86-90.

42. Murphy ML, Pichichero ME. Prospective identification and treatment of children with pediatric autoimmune neuropsychiatric disorder associated with group A streptococcal infection (PANDAS). Arch Pediatr Adolesc Med. 2002;156(4):356-361.

43. Kawikova I, Leckman JF, Kronig H, et al. Decreased numbers of regulatory $\mathrm{T}$ cells suggest impaired immune tolerance in children with Tourette syndrome: a preliminary study. Biol Psychiatry. 2007;61(3): 273-278.

44. Sayyah M, Boostani H, Pakseresht S, Malayeri A. A preliminary randomized double-blind clinical trial on the efficacy of celecoxib as an adjunct in the treatment of obsessive-compulsive disorder. Psychiatry Res. 2011;189(3):403-406.

45. Marazziti D, Presta S, Pfanner C, et al. Immunological alterations in adult obsessive-compulsive disorder. Biol Psychiatry. 1999;46(6): 810-814.
46. Denys D, Fluitman S, Kavelaars A, Heijnen CJ, Westenberg HG. Decreased TNF- $\alpha$ and NK activity in obsessive-compulsive disorder. Psychoneuroendocrinology. 2004;29(7):945-952.

47. Ravindran AV, Griffiths J, Merali Z, Ansiman H. Circulating lymphocyte subsets in obsessive compulsive disorder, major depression and normal controls. J Affect Disord. 1999;52(1-3):1-10.

48. Dale RC. Post-streptococcal autoimmune disorders of the central nervous system. Dev Med Child Neurol. 2005;47(11):785-791.

49. Hounie AG, Pauls DL, do Rosario-Campos MC, et al. Obsessivecompulsive spectrum disorders and rheumatic fever: a family study. Biol Psychiatry. 2007;61(3):266-272.

50. Seixas AA, Hounie AG, Fossaluza V, et al. Anxiety disorders and rheumatic fever: is there an association? CNS Spectr. 2008;13(12): 1039-1046.

51. Ramasawmy R, Faé KC, Spina G, et al. Association of polymorphisms within the promoter region of the tumor necrosis factor-alpha with clinical outcomes of rheumatic fever. Mol Immunol. 2007;44(8): 1873-1878.

52. Teixeira AL, Rodrigues DH, Marques AH, Miguel EC, Fontenelle LF. Searching for the immune basis of obsessive-compulsive disorder. Neuroimmunomodulation. 2014;21(2-3):152-158.

53. Swedo SE. Sydenham's chorea. A model for childhood autoimmune neuropsychiatric disorders. JAMA. 1994;272(22):1788-1791.

54. Asbahr FR, Negrao AB, Gentil V, et al. Obsessive-compulsive and related symptoms in children and adolescents with rheumatic fever with and without chorea: a prospective 6-month study. Am J Psychiatry. 1998;155(8):1122-1124.

55. Mercadante MT, Busatto GF, Lombroso PJ, et al. The psychiatric symptoms of rheumatic fever. Am J Psychiatry. 2000;157(12):2036-2038.

56. Swedo SE, Leonard HL, Mittleman BB, et al. Identification of children with pediatric autoimmune neuropsychiatric disorders associated with streptococcal infections by a marker associated with rheumatic fever. Am J Psychiatry. 1997;154(1):110-112.

57. Kurlan R. Tourette's syndrome and 'PANDAS'. Will the relation bear out? Pediatric autoimmune neuropsychiatric disorders associated with streptococcal infection. Neurology. 1998;50(6):1530-1534.

58. Perlmutter SJ, Leitman SF, Garvey MA, et al. Therapeutic plasma exchange and intravenous immunoglobulin for obsessive-compulsive disorder and tic disorders in childhood. Lancet. 1999;354(9185): $1153-1158$.

59. Singer HS, Giuliano JD, Hansen BH, et al. Antibodies against human putamen in children with Tourette syndrome. Neurology. 1998;50(6): $1618-1624$.

60. Murphy TK, Sajid M, Soto O, et al. Detecting pediatric autoimmune neuropsychiatric disorders associated with streptococcus in children with obsessive-compulsive disorder and tics. Biol Psychiatry. 2004;55(1): 61-68.

61. Allen AJ, Leonard HL, Swedo SE. Case study: a new infection-triggered, autoimmune subtype of pediatric OCD and Tourette's syndrome. J Am Acad Child Adolesc Psychiatry. 1995;34(3):307-311.

62. Fallon BA, Nields JA. Lyme disease: a neuropsychiatric illness. Am J Psychiatry. 1994;151(11):1571-1583.

63. Mell LK, Davis RL, Owens D. Association between streptococcal infection and obsessive-compulsive disorder, Tourette's syndrome, and tic disorder. Pediatrics. 2005;116(1):56-60.

64. Balkwill FR, Burke F. The cytokine network. Immunol Today. 1989;10(9):299-304.

65. Luger TA, Schwarz T. Evidence for an epidermal cytokine network. J Invest Dermatol. 1990;95(Supp1 6):100S-104S.

66. Dudbridge F. Pedigree disequilibrium tests for multilocus haplotypes. Genet Epidemiol. 2003;25(2):115-121.

67. Haddy N, Sass C, Maumus S, et al. Biological variations, genetic polymorphisms and familial resemblance of TNF- $\alpha$ and IL- 6 concentrations: STANISLAS cohort. Eur J Hum Genet. 2005;13(1): $109-117$. 
68. Monteleone P, Catapano F, Fabrazzo M, Tortorella A, Maj M. Decreased blood levels of tumor necrosis factor alpha in patients with obsessivecompulsive disorder. Neuropsychobiology. 1998;37(4):182-185.

69. Maes M. Evidence for an immune response in major depression: a review and hypothesis. Prog Neuropsychopharmacol Biol Psychiatry. 1995;19(1):11-38.

70. Hopkins SJ, Rothwell NJ. Cytokines and the nervous system I: expression and recognition. Trends Neurosci. 1995;18(2):83-88.

71. Rothwell NJ, Hopkins SJ. Cytokines and the nervous system II: actions and mechanisms of action. Trends Neurosci. 1995;18(3):130-136.

72. Fiore M, Alleva E, Probert L, Kollias G, Angelucci F, Aloe L. Exploratory and displacement behavior in transgenic mice expressing high levels of brain TNF- $\alpha$. Physiol Behav. 1998;63(4):571-576.

73. Maier SF, Watkins LR. Cytokines for psychologists: implications of bidirectional immune-to-brain communication for understanding behavior, mood, and cognition. Psychol Rev. 1998;105(1):83-107.

74. Albensi BC, Mattson MP. Evidence for the involvement of TNF and $\mathrm{NF}-\kappa \mathrm{B}$ in hippocampal synaptic plasticity. Synapse. 2000;35(2): 151-159.

75. Pickering M, O'Connor JJ. Pro-inflammatory cytokines and their effects in the dentate gyrus. Prog Brain Res. 2007;163:339-354.

76. Muller J, Roberts JE. Memory and attention in obsessive-compulsive disorder: a review. J Anxiety Disord. 2005;19(1):1-28.

77. Cavedini P, Gorini A, Bellodi L. Understanding obsessive-compulsive disorder: focus on decision making. Neuropsychol. Rev. 2006;16(1): $3-15$.

78. De Geus GF, Denys DA, Sitskoorn MM, Westenberg HG. Attention and cognition in patients with obsessive-compulsive disorder. Psychiatry Clin Neurosci. 2007;61(1):45-53.

79. Hong SB, Shin YW, Kim SH, et al. Hippocampal shape deformity analysis in obsessive-compulsive disorder. Eur Arch Psychiatry Clin Neurosci. 2007;257(4):185-190.

80. Rauch SL, Wedig MM, Wright CI. Functional magnetic resonance imaging study of regional brain activation during implicit sequence learning in obsessive-compulsive disorder. Biol Psychiatry. 2007;61(3): 330-336.

81. Balschun D, Wetzel W, Del Rey A. Interleukin-6, a cytokine to forget. Faseb J. 2004;18(14):1788-1790.

82. McCoy M, Tansey M. TNF signaling inhibition in the CNS: implications for normal brain function and neurodegenerative disease. J Neuroinflamm. 2008;5(45):1-13.

83. Murphy K, Travers P, Walport M. Janeway's Immunobiology. 7th ed. New York, NY: Garland Science; 2008.

84. Gray SM, Bloch MH. Systematic review of proinflammatory cytokines in obsessive-compulsive disorder. Curr Psychiatry Rep. 2012;14(3): 220-228

85. Himmerich H, Berthold-Losleben M, Pollmacher T. The relevance of the TNF- $\alpha$ system in psychiatric disorders. Fortschr Neurol Psychiatr. 2009;77(6):334-345.

86. Hanna GL, Veenstra-VanderWeele J, Cox NJ, et al. Genome-wide linkage analysis of families with obsessive-compulsive disorder ascertained through pediatric probands. Am J Med Genet. 2002;114(5):541-552.

87. De Mathis MA, Diniz JB, Shavitt RG, et al. Early onset obsessivecompulsive disorder with and without tics. CNS Spectr. 2009;14(7): 362-370

88. Tukel R, Ertekin E, Batmaz S, et al. Influence of age of onset on clinical features in obsessive-compulsive disorder. Depress Anxiety. 2005;21(3): 112-117.

89. Lochner C, Hemmings SM, Kinnear CJ, et al. Cluster analysis of obsessive-compulsive symptomatology: identifying obsessivecompulsive disorder subtypes. Isr J Psychiatry Relat Sci. 2008;45(3): 164-176.

90. Matsunaga H, Maebayashi K, Hayashida K, et al. Symptom structure in Japanese patients with obsessive compulsive disorder. Am J Psychiatry. 2008;165(2):251-253.
91. Rosario-Campos MC, Leckman JF, Mercadante MT, et al. Adults with early-onset obsessive-compulsive disorder. Am J Psychiatry. 2001;158(11):1899-1903.

92. Leckman JF, Katsovich L, Kawikova I, et al. Increased serum levels of interleukin-12 and tumor necrosis factor-alpha in Tourette's syndrome. Biol Psychiatry. 2005;57(6):667-673.

93. Barbosa IG, Huguet RB, Mendonca VA, et al. Increased plasma levels of soluble TNF receptor I in patients with bipolar disorder. Eur Arch Psychiatry Clin Neurosci. 2011;261(2):139-143.

94. Scalzo P, Kummer A, Cardoso F, Teixeira AL. Increased serum levels of soluble tumor necrosis factor-alpha receptor- 1 in patients with Parkinson's disease. J Neuroimmunol. 2009;216(1-2):122-125.

95. Fontenelle LF, Barbosa IG, Luna JV, de Sousa LP, Abreu MN, Teixeira AL. A cytokine study of adult patients with obsessivecompulsive disorder. Compr Psychiatry. 2012;53(6):797-804.

96. Zúniga J, Vargas-Alarcón G, Hernández-Pacheco G, Portal-Celhay C, Yamamoto-Furusho JK, Granados J. Tumor necrosis factor-alpha promoter polymorphisms in Mexican patients with systemic lupus erythematosus (SLE). Genes Immun. 2001;2(7):363-366.

97. Kroeger KM, Carville KS, Abraham LJ. The-308 tumor necrosis factor alpha promoter polymorphism effects transcription. $\mathrm{Mol}$ Immunol. 1997;34(5):391-399.

98. Sallakci N, Akcurin G, Koksoy S, et al. TNF- $\alpha$ G-308A polymorphism is associated with rheumatic fever and correlates with increased TNF- $\alpha$ production. J Autoimmun. 2005;25(2): $150-154$.

99. Westendorp RG, Langermans JA, Huizinga TW, Verweij CL, Sturk A. Genetic influence on cytokine production in meningococcal disease. Lancet. 1997;349(9069):1912-1913.

100. Brinkman BM, Zuijdeest D, Kaijzel EL, Breedveld FC, Verweij CL. Relevance of the tumor necrosis factor alpha (TNF alpha)-308 promoter polymorphism in TNF- $\alpha$ gene regulation. J Inflamm. 1995; 46(1):32-41.

101. Uglialoro AM, Turbay D, Pesavento PA, et al. Identification of three new single nucleotide polymorphisms in the human tumor necrosis factor-gene promoter. Tissue Antigens. 1998;52(4):359-367.

102. Fong CL, Siddiqui AH, Mark DF. Identification and characterization of a novel repressor site in the human tumor necrosis factor alpha gene. Nucl Acids Res. 1994;22(6):1108-1114.

103. Bayley JP, De Rooij H, Van Den Elsen PJ, Huizinga TW, Verweij CL. Functional analysis of linker-scan mutants spanning the $-376,-308$, -244 , and -238 polymorphic sites of the TNF-alpha promoter. Cytokine. 2001;14(6):316-323.

104. Drouet C, Shakhov AN, Jongeneel CV. Enhancers and transcription factors controlling the inducibility of the tumor necrosis factoralpha promoter in primary macrophages. J Immunol. 1991;147(5): 1694-1700.

105. Pociot F, D’Alfonso S, Compasso S, Scorz R, Richiardi PM. Functional analysis of a new polymorphism in the human TNF- $\alpha$ gene promoter. Scand J Immunol. 1995;42(4):501-504.

106. Kaluza W, Reuss E, Grossmann S. Different transcriptional activity and in vitro TNF- $\alpha$ production in psoriasis patients carrying the TNF- $\alpha 238$ A promoter polymorphism. J Invest Dermatol. 2000;114(6):1180-1183.

107. Dowlaty Y, Hermann N, Swardfager W, Liu H, et al.: A metaanalysis of cytokines in major depression. Biol Psychiatry. 2010; 67:446-457.

108. Sawada M, Imamura K, Nagatsu T. Role of cytokines in inflammatory process in Parkinson's disease. J Neural Transm. 2006 70(Suppl):373-381.

109. Kishimoto T. Interleukin-6 and its receptor in autoimmunity. J Autoimmun. 1992;5(1 Supp1 A):123-132.

110. Spooren A, Kolmus K, Laureys G, et al. Interleukin-6, a mental cytokine. Brain Res Rev. 2011;67(1-2):157-183.

111. Dinarello CA. Immunological and inflammatory functions of the interleukin-1 family. Annu Rev Immunol. 2009;27:519-550. 
112. Marlin SD, Springer TA. Purified intercellular adhesion molecule-1 (ICAM-1) is a ligand for lymphocyte function-associated antigen1 (LFA-1). Cell. 1987;51:813-819.

113. Dustin ML, Rothlein R, Bhan AK, Dinarello CA, Springer TA. Induction by IL 1 and interferon-gamma: tissue distribution, biochemistry, and function of a natural adherence molecule (ICAM-1). J Immunol. 1986;137(1):245-254.

114. Sironi M, Breviario F, Proserpio P, et al. IL-1 stimulates IL-6 production in endothelial cells. J Immunol. 1989;142(2):549-553.

115. Wang CC, Fu CL, Yang YH, et al. Adenovirus expressing interleukin-1 receptor antagonist alleviates allergic airway inflammation in a murine model of asthma. Gene Ther. 2006;13(19):1414-1421.

116. Nakae S, Asano M, Horai R, Iwakura Y. Interleukin-1 $\beta$, but not interleukin- $1 \alpha$, is required for T-cell dependent antibody production. Immunology. 2001;104:402-409.

117. Zheng H, Fletcher D, Kozak W, et al. Resistance to fever induction and impaired acute-phase response in interleukin-1 $\beta$-deficient mice. Immunity. 1995;3(1):9-19.

118. Marazziti D, Perez J, Cassano GB. Is obsessive-compulsive disorder caused by a second messenger imbalance? CNS Spectr. 2001;6(3): 206-209.

119. Marazziti D, Baroni S, Palego L, et al. Adenylate-cyclase activity in platelets of patients with obsessive-compulsive disorder. Neuropsychiatr Dis Treat. 2009;5:363-367.
120. Fitzgerald GA, Patrono C. The coxibs, selective inhibitors of cyclooxygenase-2. N Engl J Med. 2001;345(6):433-442.

121. Akhondzadeh S, Jafari S, Raisi F, et al. Clinical trial of adjunctive cleecoxib treatment in patients with major depressive: a double blind and placebo controlled trial. Depress Anxiety. 2009;26(7):607-611.

122. Ohishi K, Ueno R, Nishino S, Sakai T, Hayaishi O. Increased level of salivary prostaglandins in patients with major depression. Biol Psychiatry. 1988;23(4):326-334.

123. Frommberger UH, Bauer J, Haselbauer P, Fräulin A, Riemann D, Berger M. Interleukin-6 (IL-6) plasma levels in depression and schizophrenia: comparison between the acute state and after remission. Eur Arch Psychiatry Clin Neurosci. 1997;247(4):228-233.

124. Maes M, Bosmans E, De Jongh R, Kenis G, Vandoolaegh E, Neels H. Increased serum IL-6 and IL-1 receptor antagonist concentrations in major depression and treatment resistant depression. Cytokine. 1997;9(11):853-858.

125. Marazziti D, Mungai F, Masala I, et al. Normalisation of immune cell imbalance after pharmacological treatments of patients suffering from obsessive-compulsive disorder. J Psychopharmacol. 2009;23(5): 567-573.

\section{Publish your work in this journal}

The International Journal of Interferon, Cytokine and Mediator Research is an international, peer-reviewed, open-access, online journal. The focus of the journal is to publish original research, reports, editorials, reviews and commentaries on all aspects of interferon, cytokine and mediators of inflammation from labora- tory science to therapeutic indications and clinical studies. The manuscript management system is completely online and includes a very quick and fair peer-review system, which is all easy to use. Visit http://www.dovepress.com/testimonials.php to read real quotes from published authors. 